\title{
Randomized double-blind trial to evaluate the effectiveness of topical administration of propylene glycol in arsenical palmer keratosis
}

\author{
Ashrafun Naher Dina and Mir Misbahuddin
}

Division of Arsenic Research, Department of Pharmacology, Bangabandhu Sheikh Mujib Medical University, Shahbag, Dhaka, Bangladesh.

\begin{tabular}{|c|c|}
\hline \multicolumn{2}{|l|}{ Article Info } \\
\hline Received: & 20 April 2011 \\
\hline Accepted: & 22 April 2011 \\
\hline Available Online: & 27 April 2011 \\
\hline \multicolumn{2}{|c|}{ DOI: 10.3329/bjp.v5i2.7527 } \\
\hline \multicolumn{2}{|c|}{$\begin{array}{l}\text { Cite this article: } \\
\text { Dina AN, Misbahuddin M. Random- } \\
\text { ized double-blind trial to evaluate the } \\
\text { effectiveness of topical administration } \\
\text { of propylene glycol in arsenical palm- } \\
\text { er keratosis. Bangladesh J Pharmacol. } \\
\text { 2010; 5: 98-102. }\end{array}$} \\
\hline
\end{tabular}

\begin{abstract}
Keratosis, one of the earliest skin manifestations of arsenicosis, can be treated by either oral or topical formulation of drug. In this study, we examined the effectiveness and tolerance of propylene glycol for the treatment of arsenical palmer keratosis. Sixty patients of arsenicosis with palmer keratoses were randomly divided into three groups and different concentrations $(15,30$ and $45 \%$ ) of propylene glycol were applied topically into their palms once at bedtime for eight weeks. The perception of the patient about the progress of treatment was scored with "Likert scale". The mean $( \pm$ SD) score of patient's perception following completion of treatment were $1.3 \pm 1.3$ (using 15\% propylene glycol), $2.9 \pm 1.3$ (30\% propylene glycol), and $3.8 \pm 1.1(45 \%$ propylene glycol) respectively. The scores increased with higher concentrations. Thirty percent or more concentration of propylene glycol was effective for mild to severe form of keratosis. Propylene glycol was well tolerable. In conclusion, both roughness and thickness of arsenical palmer keratosis can be reduced using propylene glycol and as the concentration of the drug increases it increases its effectiveness without any significant adverse effect.
\end{abstract}

\section{Introduction}

Arsenical keratosis, thickening of keratin layer, is one of the earliest symptoms of arsenicosis (McNeer, 1934). It is most frequently seen on the thinner and lateral borders of the palms, the base and lateral aspect of the digits, the soles, heels, and toes of the feet. Keratoses are usually present as small, punctate, non-tender, horny, hard, yellowish, often symmetric, corn like papules. The diameter of the papule ranges from $0.2-1 \mathrm{~cm}$. Lesions may coalesce to form large veracious plaques. The working ability of the patient sometimes declines as it is very much dry and painful. Thus, the economy of the patient gets affected. Chronic exposure of arsenic has some serious social and mental health effects (Brinkel et al., 2009). In some cases people get socially isolated.
The beneficial effect of oral supplementation with retinol was described more than 60 years ago (Hull, 1946). The oral administration of vitamins and minerals like beta-carotene, ascorbic acid, alpha-tocopherol, folic acid, zinc, spirulina and selenium, in single or combination, were found to be effective (Ahmad et al., 1998; BACS, 2003; Misbahuddin et al., 2006). These supplementation need to be taken for a longer period (6 -12 months). The adherence of treatment is poor. Stoppage of treatment often recur the symptoms. Chronic supplementation of retinol may cause cancer. Intake of beta-carotene may cause lung cancer. There is chance of renal stone formation following intake of ascorbic acid. Zinc or selenium intake may enhance the accumulation of arsenic, if there is simultaneous intake of arsenic through drinking water. 
On the other hand, topical application of salicylic acid can often cause adverse effects like burning sensation and local irritation (Islam et al., 2007). So, newer option is needed that would be effective and tolerable. Propylene glycol has been used as smoothing and keratolytic in different conditions (Baden and Alper, 1973). Its effectiveness has not been tested for the treatment of arsenical keratosis. So, this study has been undertaken to find out the effectiveness and tolerance of propylene glycol for the treatment of arsenical keratosis.

\section{Materials and Methods}

\section{Study area}

The study was conducted at an arsenic affected area (Kamalla Union of Muradnagar Upazilla, Comilla District, about $110 \mathrm{~km}$ from Dhaka) from March to December 2010. In this Upazilla, more than $93 \%$ of tube wells are contaminated with high concentration $(<50$ $\mu \mathrm{g} / \mathrm{L})$ of arsenic.

\section{Patients}

Sixty patients of arsenical palmer keratosis were randomly included from the list of Upazilla Health Complex. Keratoses were categorized as mild, moderate and severe. In case of mild keratosis, there was hardening and roughness or gritty feeling of the skin of palm or just palpable or just visible pinhead like keratosis, scatteredly affecting the palm. Moderate keratoses were palpable and visible wart keratosis affecting palm. Severe keratoses were wart like keratosis densely or extensively distributed in whole palm.

Inclusion criteria includes adult men and women (age range 18 to 60), subject who fulfilled the following criteria was recruited as arsenicosis patient, who drank arsenic contaminated water $(>50 \mu \mathrm{g} / \mathrm{L})$, and had arsenical keratosis on palm.

Exclusion criteria includes patients having age $<18$ and $>60$ years, acutely ill patients with other major health problems, such as tuberculosis, patients getting treatment of arsenicosis, any inflammatory and infectious conditions of skin, such as eczema, psoriasis, contact dermatitis, etc., those not voluntarily agreed to participate and subjects those not fulfilled the above mentioned inclusion criteria.

Diagnosis was confirmed by history, clinical features, and presence of arsenic in drinking water and nail. The objective, nature, purpose, potential risks and benefits of all procedures of the study were explained in details to patients and informed written consent was taken from them. Photograph of the palm before and after treatment were collected. A pilot study was done on three patients for four weeks before starting the main study.

\section{Collection of specimen}

Drinking water (tube well source; $50 \mathrm{~mL}$ with one drop of $10 \%$ nitric acid) of patients and nail were collected in small polyethylene bags with ID number. All the samples were then transported to the laboratory and stored at $-20^{\circ} \mathrm{C}$ until analysis.

\section{Drug}

15,30 and $45 \%$ propylene glycol were prepared by diluting with ethanol. The preparation, blinding and labeling (coded) were done by one of the authors without mentioning the concentration. Drugs were supplied to each patient for every two weeks interval. Each patient was instructed to apply the drug on palm once daily at bed time for eight weeks. Changes after 8 weeks were presented by patient's perception score by 'Likert scale'. Regular monitoring as well as follow-up of the patients were done over cell phone.

\section{Estimation of arsenic}

The amount of arsenic in water and nail were estimated using SDDC method. In brief, inorganic arsenic was reduced to arsine $\left(\mathrm{AsH}_{3}\right)$ by zinc in strong acid solution in an arsine generator. The arsine was then passed through a scrubber containing cotton wool moistened with lead acetate into an absorber tube containing SDDC dissolved in chloroform. The arsine reacted with the silver salt, forming a soluble red color complex whose absorbance was read in a spectrophotometer (UV-VIS Spectrophotometer-1201, Shimadzu, Japan) at $525 \mathrm{~nm}$.

\section{Perception score of patient (Likert scale; Jamison, 2004)} questionnaires

When responding to a Likert questionnaire item, respondents specify their level of agreement to a statement. Likert scaling is a bipolar scaling method, measuring either positive or negative response to a statement. After the questionnaire is completed, each item may be analyzed separately or in some cases item responses may be summed to create a score for a group of items.

According to the scale the responses of progress of the patient of arsenical keratosis was grade as following and the change of the patients' perception about their disease condition was recorded. Grading of the properties to observe were Grade 0 (no change), Grade 1 (slight softening of visible lesions), Grade 2 (softening plus reduction of size of some lesions), Grade 3 (softening plus disappearance of some smaller nodules), Grade 4 (softening plus disappearance of some larger nodules), Grade 5 (deletion of maximum nodules and almost cured) and Grade 6 (fully cured).

\section{Statistical analysis}

Statistical analysis was performed using Statistical 
Package for Social Science (SPSS) software version 17 for windows. One-way analysis of variance (ANOVA) followed by Bonferroni test was done for comparisons among groups. Chi-square test was done for comparisons among groups. $\mathrm{P}$ value $<0.05$ was considered as significant.

\section{Results}

The parameters like the amount of arsenic in drinking water and nail, duration of arsenic exposure and duration of symptoms among the three groups of patients of arsenical palmer keratosis were more or less similar (Table I). Drop out cases were 13 (propylene glycol concentration, 15\%: 6 cases, 30\%: 3 cases and $45 \%$ : 4 cases).

\section{Table I}

Selected characteristics of patients

\begin{tabular}{|lrrr|}
\hline Characteristics & \multicolumn{3}{c|}{ Propylene glycol } \\
\cline { 2 - 4 } & $15 \%$ & $30 \%$ & $45 \%$ \\
\hline $\mathrm{n}$ & 20 & 20 & 20 \\
Dropout cases & 5 & 3 & 4 \\
Discarded* & 1 & 0 & 0 \\
Amount of arsenic & 674.7 & 716.7 & 690.3 \\
in water $(\mu \mathrm{g} / \mathrm{L})$ & $(147.0)$ & $(93.7)$ & $(121.0)$ \\
Duration of arsenic & 17.2 & 17.9 & 17.6 \\
exposure (years) & $(1.5)$ & $(2.3)$ & $(0.9)$ \\
Duration of symp- & 3.6 & 3.6 & 3.7 \\
toms (years) & $(1.5)$ & $(1.2)$ & $(1.5)$ \\
Amount of arsenic & 3.5 & 3.9 & 3.8 \\
in nail $(\mu \mathrm{g} / \mathrm{kg})$ & $(0.9)$ & $(1.2)$ & $(1.5)$ \\
& \multicolumn{3}{c}{} \\
Data were presented as mean $( \pm \mathrm{SD}) ;{ }^{*}$ perception was out of scale \\
\hline
\end{tabular}

The mean $( \pm$ SD) score of patients after two months of using $15 \%$ of propylene glycol were $1.4 \pm 1.0$. The scores were increased to $2.9 \pm 1.3$ and $3.9 \pm 0.9$ in patient groups receiving 30 and $45 \%$ propylene glycol respectively. Statistical comparison of scores among these groups was significant $(p<0.001)$. Besides comparisons between group of 15 and $30 \%(p<0.01) ; 15$ and $45 \% \quad(p<0.001)$ and 30 and $45 \% \quad(p<0.05)$ also showed significant difference.

Among the patients who used 15\% propylene glycol, 9 out of 14 rated their progress as 'one' (Table II). In case of $30 \%$ propylene glycol, 8 out of 17 patients rated their progress as 'four'. Among the 16 patients using 45\% propylene glycol, 3 patients scaled their progress as 'five', 7 patients as "four" and 6 patients scaled their progress as "three". Increasing concentration of propylene glycol was necessary to get higher scores.
Table II

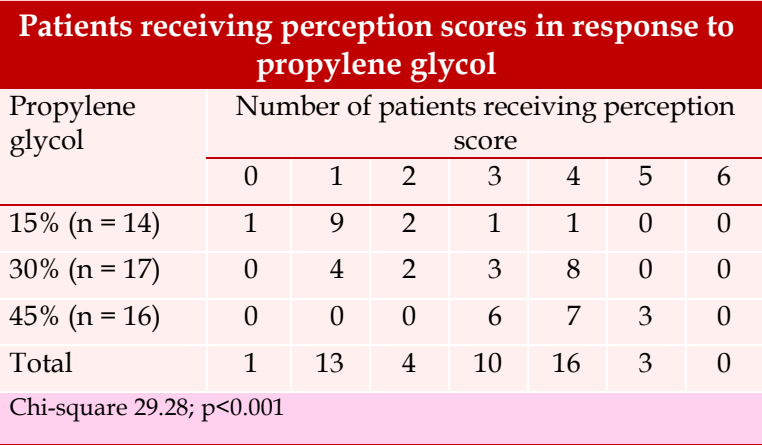

The perception score of patients of mild to moderate degree keratosis after treatment with $15 \%$ propylene glycol were $1.7 \pm 1.3$ (Table III). Severe keratosis responded less (score: $1.1 \pm 0.7$ ). On the other hand, 30$45 \%$ propylene glycol showed similar degree of scores in both mild to moderate and severe keratosis.

Table III

Perception scores of patients (mild to moderate and severe keratosis) in response to propylene glycol

\begin{tabular}{|lccc|} 
Keratosis & \multicolumn{3}{c|}{ Perception score of patients } \\
\cline { 2 - 4 } & $\begin{array}{c}\text { Propylene } \\
\text { glycol } \\
15 \%\end{array}$ & $\begin{array}{c}\text { Propylene } \\
\text { glycol } \\
30 \%\end{array}$ & $\begin{array}{c}\text { Propylene } \\
\text { glycol } \\
45 \%\end{array}$ \\
\hline $\begin{array}{l}\text { Mild to moderate } \\
(\mathrm{n}=23)\end{array}$ & $1.7 \pm 1.3$ & $2.8 \pm 1.3$ & $3.7 \pm 0.8$ \\
Severe $(\mathrm{n}=24)$ & $1.1 \pm 0.7$ & $3.0 \pm 1.3$ & $3.9 \pm 0.8$ \\
\hline
\end{tabular}

Only 7 patients $(15 \%)$ experienced with slight itching during drug application. No patient stated about deterioration after one month of stopping drug application.

\section{Discussion}

Findings of this study show that propylene glycol is effective for the treatment of arsenical keratosis and there was no significant adverse effect. Among the different percentages of the drugs the higher the percentage of the propylene glycol the more effective the drug and none of the concentrations of the drug had any significant adverse effect.

Propylene glycol is a commonly used vehicle for topical preparations. In this study, we have used for treatment purpose.

Increased thickening of stratum corneum (hyperkeratosis) may result from failure of the stratum corneum cells to be shed in a normal manner (Wells and Kerr, 1966) or increased production of keratinocytes. That mean normal desquamation process of skin 
is hampered in keratosis (Frost et al., 1966). Process of desquamation of cells can be described as follows: Corneocytes stays intact in upper level of hydrated stratum corneum where proteolytic enzymes break protein connections between corneocytes and thus corneocytes desquamate and as a result skin stays normal without dry scales (Marino, 2001).

The mechanisms by which desquamation is regulated remain to be elucidated. Given the fact that proteolytic degradation of desmosomes may be a central event in desquamation, a number of possible regulatory mechanisms can be postulated (Egelrud et al., 2000). To these belong activation of enzyme precursors, protease inhibitors in the stratum corneum (Franzke et al., 1996), changes in the lipid composition of the stratum corneum intercellular space (Williams, 1991) water content (Warner, 1986) and $\mathrm{pH}$ of the stratum corneum (Ohman and Vahlquist, 1994) and the action of modifying enzymes such as various glycosidases (Walsh and Chapman, 1991).

Propylene glycol follows the water retaining process to regulate desquamation. The water is drawn from the deeper dermis, rarely the environment. Propylene glycol penetrates the stratum cornium faster than other solvents (Vaddi et al., 2002). Propylene glycol as a humectant agent attracts water to the skin. The hydration of the stratum corneum normalizes the intercellular lipids and the natural desquamation process. Humectants also mimic the role of natural hydrophilic humectants in the stratum corneum. The skin becomes more resistant to drying conditions (Marino, 2001). Through this repeated hydration process keratosis is described to be decreased. And there were no remarkable side effects. Only fifteen percent of the total patients' mentioned about slight itching during the time of drug application and that was within their allowable limit. So it can be said that propylene glycol is effective for arsenical keratosis treatment without any remarkable side effects up to $45 \%$ of concentrations.

\section{Conclusion}

Three patients were cured whereas all of the arsenical palmer keratoses patients got remarkable improvement without any adverse effect after two months topical application of $45 \%$ propylene glycol solution.

\section{Ethical Issue}

The ethical issue of this study was reviewed and approved by the Ethical committee of Bangabandhu Sheikh Mujib Medical University. All subjects enrolled in this study were explained about the nature and purpose of the study in easily understandable local language (Bangla). An informed written consent was taken from each patient.

\section{Conflict of Interest}

The authors declare no conflict of interest.

\section{References}

Ahmad SK, Faruquee MH, Sayed MHSU, Khan MH, Hadi SA, Khan AW. Chronic arsenic poisoning: Management by vitamin A, E, C regimen. J Pre Social Med (JOPSOM). 1998; 17: 19-26.

Baden HP, Alper JC. A keratolytic gel containing salicylic acid in propylene glycol. J Invest Dermatol. 1973; 6: 330-33.

Brinkel J, Md, Khan MMH, Kraemer A. Systematic review of arsenic exposure and its social and mental health effects with special reference to Bangladesh. Int J Environ Res Public Health. 2009; 6: 1609-19.

Bangladesh Arsenic Control Society. Double blind, randomized, placebo-controlled trial of anti-oxidant vitamins and minerals in the treatment of chronic arsenic poisoning in Bangladesh, BACS. Dhaka, Bangladesh, 2003; 1 -103.

Egelrud T. Desquamation in the stratum corneum. Acta Derm Venereol. 2000; Supp 208: 44-45.

Franzke CW, Baici A, Bartels J, Christophers E, Wiedow O. Antileukoprotease inhibits stratum corneum chymotryptic enzyme: Evidence for a regulative function in desquamation. J Biol Chem. 1996; 271: 21886-89.

Frost P, Weinstein GD, Van Scott EJ. The ichthyosiform dermatoses. II. Autoradiographic studies of epidermal proliferation. J Invest Dermatol. 1966; 47: 561-67

Hall AF. Arsenical keratosis disappearing with vitamin A therapy. Derm Syph. 1946; 53: 154.

Islam AZMM, Sikdar S, Biswas AK, Islam Z, Hadiuzzaman, Misbauddin M, Khandaker S, Mahmud I, Ahmad SA. Randomized controlled trial to evaluate the effectiveness of topical use of salicylic acid for treatment of keratosis in arsenicosis patient. Applied research on arsenic in Bangladesh, 2007, p 101.

Marino C. Skin physiology, irritants, dry skin and moisturizers. Washington State Department of Labor and Industries 2001, August 2001.

McNeer G. Arsenical keratoses and epitheliomas. Ann Surg. 1934; 99: 348-53.

Misbahuddin M, Islam AZMM, Khandker S, Mahmud IA, Islam N, Anjumanara. Efficacy of spirulina extract plus zinc in patients of chronic arsenic poisoning: A randomized 
placebo-controlled study. Clin Toxicol. 2006; 44: 135-41.

OEhman $\mathrm{H}$, Vahlquist A. In vivo studies concerning a $\mathrm{pH}$ gradient in human stratum corneum and upper epidermis. Acta Derm Venereol (Stockh). 1994; 74: 375-79.

Vaddi HK, HO PC, Chan YW, Chan SY. Oxide terpenes as human skin penetration enhancers of haloperidol from ethanol and propylene glycol and their modes of action on stratum corneum. Biol Pharm Bull. 2003; 26: 220-28.
Walsh A, Chapman SJ. Sugars protect desmosome and corneosome glycoproteins from proteolysis. Acta Dermatol Res. 1991; 283: 174-79.

Warner RR. Water content from analysis of freeze-dried thin section. J Microsc. 1986; 142: 363-69.

Wells RS, Kerr CB. The histology of ichthyosis. J Invest Dermatol. 1966; 46: 530-35. 